\title{
Prevalence in the utilization of text message services under the mother and child tracking system of India: a cross sectional study from Pune district, Maharashtra, India
}

\author{
Ankita Sharma*, Aakash Shinde, Anita Kar
}

Interdisciplinary School of Health Sciences, Savitribai Phule Pune University, Pune, Maharashtra, India

Received: 24 June 2016

Accepted: 12 July 2016

*Correspondence:

Ankita Sharma,

E-mail: ankita.sharma.us@gmail.com

Copyright: ( ) the author(s), publisher and licensee Medip Academy. This is an open-access article distributed under the terms of the Creative Commons Attribution Non-Commercial License, which permits unrestricted non-commercial use, distribution, and reproduction in any medium, provided the original work is properly cited.

\section{ABSTRACT}

Background: The mother and child tracking system (MCTS) is a surveillance system to track pregnant women and children. It includes a provision of short message service (SMS), that alerts registered beneficiaries about outstanding services. This study determined the prevalence of use of SMS by beneficiaries of MCTS from Pune district, Maharashtra.

Methods: A cross-sectional study was carried out among respondents availing antenatal care or immunization services at ten randomly selected primary health centres (PHCs) in Pune district. Data was collected after consent using a semi-structured questionnaire. Data was analyzed using Statistical Package for Social Sciences (19.0 version). Results: The study included 205 pregnant women and 236 parents of children. Almost $66 \%$ of respondents owned a mobile phone and majority $(91 \%)$ were residents in areas with network coverage. Among respondents of nine PHCs, $17 \%$ of respondents had heard of, and $14 \%$ reported having received a text message of outstanding services on the mobile phone. At one PHC where the auxiliary nurse midwife was sending text message reminders in local language from her mobile phone, $43 \%$ respondents were aware of text messaging services and almost $24 \%$ respondents reported receipt of text messages. Education level $(\mathrm{p}<0.00)$ and possession of mobile phone $(\mathrm{p}<0.004)$ were significantly associated with receipt of text messages.

Conclusions: Low prevalence of use of text messaging service by beneficiaries stresses the need to increase awareness of these services. Text messages in local language have an advantage over the English language at the community level.

Keywords: mHealth, Short message service, Mother and child tracking system, India

\section{INTRODUCTION}

Adequate communication of information is essential for the delivery and receipt of healthcare services. Traditionally, public health messages were delivered through community health workers and media such as newspapers, radio, and television. Over the past decade use of mobile phones has increased significantly in India, with over 1000 million subscribers. ${ }^{1}$ Mobile phones present an opportunity to provide health services, especially in rural and resource-poor settings, because of their deeper penetration, extensive network coverage, and ease of use. ${ }^{2}$ Mobile Health, popularly known as mHealth can be used to disseminate educational information, reminders, emergency response, support and monitoring. ${ }^{3}$ The use of mHealth has been reported from several lowincome settings especially in the area of maternal and child health. Studies indicate that mobile phone interventions are associated with increased antenatal care attendance, and improving birth outcomes. ${ }^{4,5}$ It highlights 
the feasibility of using mHealth as a tool for providing health information to the community.

In 2009, the Government of India launched a maternal and child health surveillance, termed the mother and child tracking system (MCTS). The MCTS registers pregnant women from first antenatal care (ANC) presentation, till up to 42 days postpartum and newborn children up to five years of age. Data of beneficiaries who avail health services from the public health system are entered into the MCTS web portal by data entry operators. This data automatically generates monthly work plans for auxiliary nurse midwife (ANM) which contains information on either ANC, Post Natal Care (PNC) or immunization services to be delivered to the registered woman or child. ${ }^{6}$

The MCTS system also generates an automatic text message (short message service (SMS)) to the registered beneficiary to alert them about their outstanding services. Other information delivered through SMS includes healthy practices during $\mathrm{ANC}, \mathrm{PNC}$, and the importance of immunization for children.

Since the launch of MCTS, there has been no study which has reported utilization of services from the beneficiary's point of view. Also, no study has reported acceptability and attitude towards text messaging system of MCTS by the recipient. Therefore, we conducted a study to determine the prevalence of use of short messaging services and barriers perceived by the beneficiaries and community health workers (CHWs) for using services of MCTS.

\section{METHODS}

\section{Study design and setting}

This descriptive, cross-sectional study was carried out at 10 primary health centres (PHCs) of Pune district, Maharashtra, India. Ten out of 96 PHCs were randomly selected from Pune district. Out of the ten selected PHCs, one PHC was tribal while rest nine were non-tribal. In nine PHCs, the MCTS was functioning as per norms, that is upon entry of beneficiary data, text messages were being generated and transmitted to the CHWs and beneficiary. At one PHC, the ANM was sending text message reminders to beneficiaries in local (Marathi) language about their outstanding services so that all of them receive timely services.

\section{Sample, inclusion and exclusion criteria}

A pilot study done at Khadkala PHC in Pune district had shown a prevalence of $3.5 \%$ use of text messaging service by beneficiaries of MCTS. Considering prevalence data, a sample size of 424 was calculated using the formula for descriptive studies $(n=z 2 p q / d 2){ }^{7}$ The sample size was increased to 466 assuming $10 \%$ non-response. All pregnant women and parents of children who were previously registered with MCTS were enrolled until the sample size was attained over a period of 10 weeks between the months of December 2014 and January 2015. We targeted minimum 45 beneficiaries per PHC in our study.

\section{Data collection}

Data was collected using a pretested semi-structured questionnaire by face to face interview at ANC and immunization camp of respective PHC. We interviewed 441 respondents.

\section{Ethical and regulatory approvals}

The study was explained to the participants, and their written consent was obtained in local (Marathi) language. Ethical approval was obtained from Institutional Ethics Committee of Savitribai Phule Pune University. A prior permission was obtained from District Health Officer of Pune district to conduct the study.

\section{Data analysis}

Data was analyzed using Statistical Package for Social Sciences (SPSS) version 19. We determined the frequencies and distribution of demographic and mobile phone usage characteristics. Chi-square tests were performed to test the observed differences.

\section{RESULTS}

\section{Socio-demographic characteristics}

The study sample included 441 respondents, consisting of 205 pregnant women and 236 parents of children present at the PHCs for services. The age of the respondents ranged from 16 to 40 years with mean age of 23 years. Among the respondents, $121(27.4 \%)$ had completed middle school (5-9 years of education), and $111(25 \%)$ had completed high school level (10 years of education). Out of 441 respondents, $67(15.1 \%)$ had completed graduation level education. Among the respondents, 293 (66. $4 \%$ ) were unemployed. Majority $(90 \%)$ were living in joint families. Out of 441, $421(95.4 \%)$ were Hindu and $20(4.5 \%)$ were Muslim. There was a difference between the two groups of beneficiaries in age distribution as over $65 \%$ of the pregnant women were under 23 years old, while over $60 \%$ of parents were over the age of 24 years. However, the difference was not statistically significant $(\mathrm{p}<0.49)$ (Table 1$)$. 
Table 1: Socio demographic characteristics of respondents $(\mathrm{N}=441)$.

\begin{tabular}{|c|c|c|c|}
\hline Characteristics of respondents & $\begin{array}{l}\text { Pregnant women } \\
\mathrm{n}=205(\%)\end{array}$ & $\begin{array}{l}\text { Parents of children } \\
\mathrm{n}=236(\%)\end{array}$ & $\mathrm{N}=\mathbf{4 4 1}(\%)$ \\
\hline \multicolumn{4}{|l|}{ Age (years) } \\
\hline $16-21$ & $83(40.4)$ & $47(19.9)$ & $130(29.4)$ \\
\hline $22-23$ & $51(24.8)$ & $42(17.7)$ & $93(21)$ \\
\hline $24-25$ & $39(19)$ & $70(29.6)$ & $109(24.7)$ \\
\hline$>25$ & $30(14.6)$ & $74(31.3)$ & $104(23.5)$ \\
\hline Don’t know & $2(0.9)$ & $3(1.2)$ & $5(1.3)$ \\
\hline \multicolumn{4}{|l|}{ Education Level } \\
\hline Graduate or post graduate & $19(9.2)$ & $48(20.3)$ & $67(15.1)$ \\
\hline Intermediate or post high school diploma & $42(20.4)$ & $50(21.1)$ & $92(20.8)$ \\
\hline High school & $56(27.3)$ & $55(23.3)$ & $111(25.1)$ \\
\hline Middle school & $61(29.7)$ & $60(25.4)$ & $121(27.4)$ \\
\hline Primary school & $10(4.8)$ & $12(5)$ & $22(4.9)$ \\
\hline Illiterate & $17(8.2)$ & $10(4.2)$ & $27(6.1)$ \\
\hline Don’t Know & 0 & $1(0.4)$ & $1(0.2)$ \\
\hline \multicolumn{4}{|l|}{ Occupation } \\
\hline Unemployed & $141(68.7)$ & $152(64.4)$ & $293(66.4)$ \\
\hline Farmers & $44(21.4)$ & $42(17.7)$ & $86(19.5)$ \\
\hline Skilled Worker & $17(8.2)$ & $42(17.7)$ & $59(13.3)$ \\
\hline Student & $3(1.4)$ & 0 & $3(0.6)$ \\
\hline \multicolumn{4}{|l|}{ Family Type } \\
\hline Joint & $176(85.5)$ & $223(94.4)$ & $399(90.4)$ \\
\hline Nuclear & $29(14.1)$ & $13(5.5)$ & $42(9.5)$ \\
\hline \multicolumn{4}{|l|}{ Religion } \\
\hline Hindu & $195(95.1)$ & $226(95.7)$ & $421(95.4)$ \\
\hline Muslim & $10(4.8)$ & $10(4.2)$ & $20(4.5)$ \\
\hline
\end{tabular}

Table 2: Usage of mobile phone among respondents.

\begin{tabular}{|c|c|c|c|}
\hline Characteristics & $\begin{array}{l}\text { Pregnant women } \\
\mathrm{n}=205(\%)\end{array}$ & $\begin{array}{l}\text { Parents of children } \\
\mathrm{n}=236(\%)\end{array}$ & $\mathrm{N}=441(\%)$ \\
\hline \multicolumn{4}{|l|}{ Possession of mobile phone } \\
\hline Yes & $121(59)$ & $170(72)$ & $291(65.9)$ \\
\hline No & $84(40.9)$ & $66(28)$ & $150(34)$ \\
\hline Access to mobile phone who don't posses own & $\mathrm{n}=84(\%)$ & $\mathrm{n}=66(\%)$ & $\mathrm{n}=150(\%)$ \\
\hline Yes & $68(80.9)$ & $55(83.3)$ & $123(82)$ \\
\hline No & $16(19)$ & $11(16.6)$ & $27(18)$ \\
\hline \multicolumn{4}{|l|}{ Range for mobile network } \\
\hline Yes & $181(88.2)$ & $220(93.2)$ & $401(91)$ \\
\hline No & $4(1.9)$ & $3(1.2)$ & $7(1.5)$ \\
\hline Sometimes & $8(3.9)$ & $3(1.2)$ & $11(2.4)$ \\
\hline Don’t know & $1(1.9)$ & $1(0.4)$ & $2(0.4)$ \\
\hline NA & $11(5.3)$ & $9(3.8)$ & $20(4.5)$ \\
\hline Purpose of using mobile phone who owns & $\mathrm{n}=121(\%)$ & $\mathrm{n}=170(\%)$ & $\mathrm{n}=291(\%)$ \\
\hline Voice call & $58(47.9)$ & $74(43.5)$ & $132(45.3)$ \\
\hline Voice call + SMS & $63(52.1)$ & $96(56.4)$ & 159 (54.6) \\
\hline \multicolumn{4}{|l|}{ Ability to read SMS in the English language } \\
\hline Yes & $144(70.2)$ & $182(77.1)$ & $326(73.9)$ \\
\hline No & $61(29.7)$ & $54(22.8)$ & $115(26.1)$ \\
\hline
\end{tabular}




\section{Ownership and use of mobile phone among respondents}

Of $441,291(65.9 \%)$ had own mobile phones. Out of 150 (34\%) who did not possess mobile phones, $123(82 \%)$ had access to the mobile phones as it was owned by husband or family member residing in the household. The $27(18 \%)$ beneficiaries who had not provided own or any close person's contact, were found to have provided the phone numbers of neighbors or distant relatives, or in some instances the ANM has inserted her own mobile number as these individuals were unable to provide any number. More than $90 \%$ of respondents reported range for mobile network at their home. The principal purpose of using mobile phones was voice call $(45.3 \%)$ and voice call and text message both (54.6\%). Among all respondents, $326(73.9 \%)$ respondents stated that they were able to read the SMS in the English language. Regarding possession of mobile phones, more parents $(72 \%)$ than pregnant women $(59 \%)$ had own mobile phones (Table 2). However, there was no difference in access to mobile between both groups.

\section{Prevalence of use of text messaging services under MCTS}

Table 3 shows prevalence of use of text message service by beneficiaries of MCTS. The majority (95.2\%) had provided phone number during registration. At nine PHCs, of 365 respondents, $65(17.6 \%)$ were aware of text messaging service while $52(14 \%)$ confirmed receipt of text messages on the mobile phone number provided during registration. Univariate analysis showed that there was statistically significant association between education level, possession of the mobile phones and receipt of a text message (Table 4). In one of the PHCs where the ANM was sending text messages in the local language, 33 out of 76 respondents $(43.4 \%)$ were aware of text messaging service, and $19(25 \%)$ of them confirmed receipt of text message reminders. 15 out of 76 respondents $(23.7 \%)$ reported that they received a text message in local (Marathi) language.

\section{Barriers perceived in utilization of text messaging service}

\section{By beneficiaries}

About $82 \%$ of respondents stated not being aware of the text messaging services. English language used for messaging was another barrier to utilization of the service as $26.1 \%$ of respondents were unable to read the English language. Lack of ownership of mobile phone was the next stated barrier for using text messaging service $(34 \%)$.

Table 3: Prevalence of use of text message service by beneficiaries of MCTS*.

\begin{tabular}{|c|c|c|c|}
\hline Variable & $\begin{array}{l}\text { Pregnant women, } \mathrm{n}=205 \\
(\%)\end{array}$ & $\begin{array}{l}\text { Parents of children, } n=236 \\
(\%)\end{array}$ & $\mathrm{N}=441(\%)$ \\
\hline \multicolumn{4}{|c|}{$\begin{array}{l}\text { Phone number provided for registration at } \\
\text { PHC }\end{array}$} \\
\hline Yes & $195(95.1)$ & $225(95.3)$ & $420(95.2)$ \\
\hline No & $10(4.8)$ & $11(4.6)$ & $21(5)$ \\
\hline \multicolumn{4}{|c|}{ Awareness of text message service $(n=365)$} \\
\hline Yes & $26(15)$ & $39(19.8)$ & $65(17.6)$ \\
\hline No & $145(83.8)$ & $159(81.1)$ & $300(82.1)$ \\
\hline \multicolumn{4}{|c|}{$\begin{array}{l}\text { Receipt of text message about health services } \\
(n=365)\end{array}$} \\
\hline Yes & $27(15.6)$ & $25(12.7)$ & $52(14)$ \\
\hline No & $125(72.2)$ & $143(72.9)$ & $268(73.4)$ \\
\hline Don't know & $13(7.5)$ & $24(12.2)$ & $37(10)$ \\
\hline NA & $5(2.8)$ & $4(2)$ & $8(2.1)$ \\
\hline
\end{tabular}

*Data excludes 76 beneficiaries (32 pregnant women and 44 parents of children) from a PHC where the ANM was sending text messages in the Marathi language.

\section{By auxiliary nurse midwife (ANM)}

Among the ANMs which were interviewed, interrupted supply of electricity and internet services at PHC's were reported to be a major challenge for them. The minimum time required to enter information of one beneficiary was stated to be around 15-20 minutes. This led to a delay in entry of information of beneficiaries into the software. ANMs were found to be updating information from home, cyber cafés or village panchayat office after finishing regular duties at the PHC. In all the PHCs sampled in the study, there was no data entry operator for entry of beneficiaries data in MCTS software. Among all interviewed ANM, two reported a concern about the double entry of few beneficiaries in the MCTS software, 
as women did not provide information about previous registration at the rural hospital or other PHCs. This was also reported to be a major source of loss to follow-up of women registered under the MCTS. Migrants such as construction workers and sugarcane cutters were another source of loss to tracking, as these beneficiaries failed to inform the PHCs before migration.

Table 4: Factors associated with receipt of text message.

\begin{tabular}{|lllllll|}
\hline Factor & \multicolumn{2}{l}{ Pregnant women $\mathbf{n = 2 0 5}(\%)$} & \multicolumn{2}{l}{ Parents of children $\mathbf{n = 2 3 6 ( \% )}$} & \multicolumn{2}{l|}{ Total $\mathbf{N}=\mathbf{4 4 1}(\%)$} \\
\hline Education level & $\mathrm{N}(\%)$ & P-values & $\mathrm{N}(\%)$ & P-values & $\mathrm{N}(\%)$ & P-values \\
\hline$<10$ & $90(43.9)$ & 0.000 & $76(32.3)$ & 0.000 & $166(37.6)$ & 0.000 \\
\hline$>10$ & $115(56.1)$ & & $160(67.7)$ & & $275(62.3)$ & \\
\hline $\begin{array}{l}\text { Possession of } \\
\text { mobile phone }\end{array}$ & $121(59)$ & 0.002 & $170(72)$ & 0.000 & $291(65.9)$ & 0.004 \\
\hline
\end{tabular}

\section{DISCUSSION}

Access to a mobile phone in India has increased over time mainly due to a decrease in its price, placing India at the second place among top mobile subscribers in the world. ${ }^{8}$ Extensive network availability in rural areas as found in the study makes it a low cost and a promising tool for communication between health providers and beneficiaries of MCTS. This study investigated the prevalence and barriers perceived by beneficiaries and CHWs in the utilization of services under mother and child tracking system in Pune district of Maharashtra state. The findings of this study showed that $66 \%$ of respondents possessed their mobile phone, and $91 \%$ resided in areas where there was mobile network coverage, underlining the enormous potential of mHealth technology. However, the study data revealed that only $17.6 \%$ of total beneficiaries were aware of text message service and out of them $14 \%$ received messages from MCTS. When text messages were sent in the local (Marathi) language, more than $40 \%$ of beneficiaries were aware of text messaging service and $25 \%$ confirmed receipt of text message informing them about their outstanding services. This finding of the study underlines the importance of sending a text message in a local language which is understandable by the rural pregnant women and parents of children.

The mHealth strategy cannot be used as a stand-alone intervention. This was illustrated by the data that $82 \%$ of respondents were unaware of such services. Thus, advertising at all public health centers is recommended to make the community aware of text messaging services available for pregnant women and children. In South Africa, Cell-Life's MAMA SMS program of mHealth interventions had advertised through posters and pamphlets at their health facilities, and also health workers explained the program to the beneficiaries. This resulted in a high awareness and acceptability among beneficiaries. ${ }^{9}$ The other learning from the study was the need for supportive infrastructure such as uninterrupted electric supply and internet connection to ensure the functioning of the mHealth intervention. Another required input was the organization of data entry support staff, as leaving this activity with the ANM resulted in a lack of time for the activity.

In conclusion, the data from this study suggests that text messages through mobile phone could be a valuable tool in reminding the community about healthy practices and for reminding beneficiaries about various maternal and child health services available at the health center. The mHealth activity has to be backed up by appropriate communication by health providers to the beneficiaries about text messaging service at the time of registration.

The study finding suggests that beneficiaries who possess own mobile phones and were educated post-secondary level were more likely to receive text messages. This underlines that traditional methods of health communication have to go hand in hand with the use of the mHealth tool, especially in more vulnerable communities. The limitation of this study is that further in-depth qualitative studies are needed to explore beneficiaries' attitude about mHealth services at a larger level, including indigent urban settings to get a wider insight into the potential of the mHealth tool.

\section{CONCLUSION}

There was a low prevalence of use of text message services of MCTS by beneficiaries. Post-secondary education, possession of the own mobile phone and local language messages are likely to increase utilization of this service. Infrastructural support such as uninterrupted electricity, internet services and appropriately skilled human resource for data entry is required to support the service. Traditional methods of communication are needed for initial familiarization of beneficiaries about the availability of this service. 


\section{ACKNOWLEDGEMENTS}

Authors would like to thank the study participants for participating in the study, Charuta Gokhale for technical assistance, and the District Health Officer, Pune district for permission to conduct the study.

Funding: Departmental Research Development Programme, Savitribai Phule Pune University

Conflict of interest: None declared

Ethical approval: The study was approved by the Institutional Ethics Committee of Savitribai Phule Pune University

\section{REFERENCES}

1. Telecom Regulatory Authority of India (2016). Highlights of Telecom Subscription Data as on $31^{\text {st }}$ January 2016. Available at: http://www.trai.gov.in/ WriteReadData/PressRealease/Document/PR-TSDFeb-10042015.pdf Accessed on $3^{\text {rd }}$ May 2016.

2. World Health Organization. mHealth: New horizons for health through mobile technologies. Glob Obs eHealth Ser. 2011;3:112.

3. Sondaal SFV, Browne JL, Amoakoh-Coleman M, Borgstein A, Miltenburg AS, Verwijs M, et al. Assessing the effect of mHealth interventions in improving maternal and neonatal care in low-and middle-incom countries: a systematic review. PLoS ONE. 2016;11(5):e0154664

4. Lund S, Nielsen B, Hemed M, Boas I, Said A, Said $\mathrm{K}$, et al.: Mobile phones improve antenatal care attendance in Zanzibar: a cluster randomized controlled trial. BMC Pregnancy and Childbirth. 2014;14:29.

5. Lund S, Rasch V, Hemed M, Boas IM, Said A, Said $\mathrm{K}$, et al. Mobile phone intervention reduces perinatal mortality in zanzibar: secondary outcomes of a cluster randomized controlled trial. JMIR Mhealth Uhealth. 2014;2(1):e15.

6. Gera R, Muthusamy N, Bahulekar A, Sharma A, Singh P, Sekhar A, et al.: An in-depth assessment of India's Mother and Child Tracking System (MCTS) in Rajasthan and Uttar Pradesh; BMC Health Services Research. 2015;15:315.

7. Daniel WW. Biostatistics: a foundation for analysis in the health sciences. $7^{\text {th }}$ edition. New York: John Wiley \& Sons. 1999.

8. Central Intelligence Agency. The World Factbook, 2016. Available at: https://www.cia.gov/library/ publications/resources/the-worldfactbook/geos/in.html Accessed 11 May 2016.

9. Supporting pregnant women and new mothers in South Africa Cell-Life's MAMA SMS; World Health Organization, 2013. Available at: http://apps.who.int/iris/bitstream/10665/92808/1/W HO_RHR_13.13_eng.pdf. Accessed on 29 September 2015.

Cite this article as: Sharma A, Shinde A, Kar A. Prevalence in the utilization of text message services under the mother and child tracking system of India: a cross sectional study from Pune district, Maharashtra, India. Int J Community Med Public Health 2016;3: 2319-24. 